Ansell N, Tsoeu-Ntokoane S and Hajdu F (in press and online) 'Women's changing domestic responsibilities in neoliberal Africa: a relational time-space analysis of Lesotho's garment industry' Gender, Place and Culture

\title{
Women's changing domestic responsibilities in neoliberal Africa: a relational time-space analysis of Lesotho's garment industry
}

Nicola Ansell*, Seroala Tsoeu and Flora Hajdu

Nicola Ansell, Brunel University

Centre for Human Geography

School of Health Sciences and Social Care

Brunel University

Uxbridge

West London

UB8 3PH

+44(0)1895266085

nicola.ansell@brunel.ac.uk

Seroala Tsoeu, National University of Lesotho

Seroala Tsoeu-Ntokoane

Political and Administrative Studies

National University of Lesotho

Roma 
Ansell N, Tsoeu-Ntokoane S and Hajdu F (in press and online) 'Women's changing domestic responsibilities in neoliberal Africa: a relational time-space analysis of Lesotho's garment industry' Gender, Place and Culture

Lesotho

$+26652213657$

stsoeu@gmail.com

Flora Hajdu, Swedish University of Agricultural Sciences

Division of Rural Development

Department of Urban and Rural Development

Swedish University of Agricultural Sciences

Ulls väg 28

Box 7012

75007 Uppsala

Sweden

+4618672162

Flora.hajdu@slu.se

Word count: 9998 (no figs)

CN: yes

ACKN: no 
Ansell N, Tsoeu-Ntokoane S and Hajdu F (in press and online) 'Women's changing domestic responsibilities in neoliberal Africa: a relational time-space analysis of Lesotho's garment industry' Gender, Place and Culture

\title{
Women's changing domestic responsibilities in neoliberal Africa: a relational time-space analysis of Lesotho's garment industry
}

\author{
Since 2001 when Lesotho embraced the neoliberal African Growth and Opportunities Act \\ that offers preferential access to the US market, its garment industry has expanded \\ dramatically to become the nation's leading employer. Elsewhere, large-scale employment \\ of women in low-paid factory jobs has entailed spatial restructuring of gender and age \\ relations. Lesotho is a distinctive context, with socio-spatial relations historically adjusted \\ to male labour migration, high levels of contemporary male unemployment and alarming \\ AIDS prevalence. Based on semi-structured interviews with 40 female factoryworkers and \\ 37 dependents, this article applies a relational time-space analysis to explore how financial \\ and spatio-temporal aspects of factory employment articulate to alter women's \\ relationships with those for whom they have culturally determined responsibilities: their \\ children, those suffering from ill health and their (generally rural) home communities. The \\ analysis highlights that such employment is not merely adding to women's responsibilities, \\ but transforming how they are able to undertake social reproduction, as practical, social \\ and emotional roles are converted to largely financial obligations.
}

Keywords: neoliberalism; garment sector; time-space; social reproduction; Lesotho

\section{Introduction}

Poverty in Africa, as elsewhere, is often attributed to under- or unemployment (Dicken 2003), with export-led industrialisation promoted as the neoliberal solution. Neoliberalism does not, however, simply create jobs - it reshapes societies in complex ways (Peck and Tickell 2002; Harrison 2010). Furthermore, poverty is multidimensional, and not simply characterised by low incomes. A narrow focus on income poverty neglects important aspects of individual and collective wellbeing that require fulfilment of social reproductive roles; roles that socially 
Ansell N, Tsoeu-Ntokoane S and Hajdu F (in press and online) 'Women's changing domestic responsibilities in neoliberal Africa: a relational time-space analysis of Lesotho's garment industry' Gender, Place and Culture

constructed gender ideologies allocate disproportionately to women. The fact that employment created through export-led industrialisation is dominated by women, therefore, affects both women's wellbeing and that of other family members, and entails renegotiation of intrahousehold relations and roles.

In Lesotho, export-led garment manufacturing expanded dramatically with changes in the international trading environment, particularly the US African Growth and Opportunities Act (AGOA) in 2001. As elsewhere, the garment factories employ a predominantly female workforce. However, Lesotho's history of near-universal male labour migration and the world's third highest HIV prevalence mediate industrialisation's effects on poverty and wellbeing.

Werner (2010) has called for a 'spatialisation' of feminist research on global production; we argue that not only spatial but spatio-temporal aspects of industrialisation are significant. In this article we explore how the time-spaces of factory employment in Lesotho intersect with its monetary dimensions to influence women's relationships with, and responsibilities towards, their children, sick relatives and rural families. Applying a relational time-space approach illuminates relatively neglected aspects of neoliberal export-led industrialisation, notably a shift in women's domestic responsibilities from practical, social and emotional carer to financial provider.

\section{The globalising garment industry}

Of export-oriented industries, the garment industry was the first to 'globalise' and is now uniquely widespread (Dicken 2003). Its mobility is attributable to three factors. First, as few processes can be automated, labour costs are crucial: the industry seeks out low wage economies (ibid). Second, information technology allows firms to employ complex global supply chains, 
Ansell N, Tsoeu-Ntokoane S and Hajdu F (in press and online) 'Women's changing domestic responsibilities in neoliberal Africa: a relational time-space analysis of Lesotho's garment industry' Gender, Place and Culture

easily switching orders to the cheapest source (Standing 1999). The third factor is the shifting tariff environment. Until it ended in December 2004, the Multi-Fibre Arrangement (MFA) used quotas to limit exports from Third World garment producers to protect Western manufacturers (Dicken 2003). Asian producers, having exhausted their quotas, switched production to Africa to exploit unused quota (Kaplinksy 2008). Preferential Trade Agreements are also significant, with deals such as AGOA facilitating new trading relationships.

The garment industry's mobility is problematic. Responsiveness to labour costs keeps wages low and hours long, and volatile demand means contracts are insecure (Elson 1999). The industry's mobility also undermines longer-term security. At the onset of the global financial crisis (2007-2008), garment exports from Lesotho to the US fell by 18 percent (agoa.info 2011). Regulation is problematic: powerful but distant buyers pressure manufacturers to keep wages low (Traub-Werner and Cravey 2002). Demands for improved pay or conditions incite unemployment if firms shift investment elsewhere (Heintz 2004).

\section{Socio-spatial impacts of garment manufacture}

Research into the garment industry's social impacts has focused primarily on gender, as most employees are women. The 'global feminisation of labour' (Standing 1999), beginning in the 1970s, confounded Boserup's (1970) thesis of women's exclusion from industrialisation, but women were confined to lower-paid, less secure, less regulated jobs than men (Elson 1999). Employers' requirements for 'nimble-fingered' workers mask discrimination through labour force segmentation. Considered a secondary labour market, women's wages are assumed to 
Ansell N, Tsoeu-Ntokoane S and Hajdu F (in press and online) 'Women's changing domestic responsibilities in neoliberal Africa: a relational time-space analysis of Lesotho's garment industry' Gender, Place and Culture

supplement those of male breadwinners (Green 2003; Pearson 1998). Reserving certain occupations for women minimises wage bills (Bandy 2000).

While firms benefit from employing women, women's gains are less clear-cut. Few workingwomen spend their earnings freely and most retain heavy domestic responsibilities (Elson 1999). Some argue women gain little power within their households (Hewamanne 2006; Tiano 1994); others suggest some women's earnings have transformatory potential (Kabeer 2000), offering leverage within the household (Chant and McIlwaine 1995), increased respect, social standing and 'voice' (Khosla 2009), greater spatial freedom (Green 2003) and various other gains (Amin et al 1998). Garment factorywork often entails migration to urban centres (Webber et al 2010; Werner 2010) and even across national borders (Crinis 2010), which transforms lives and can exacerbate vulnerability (Webber et al 2010, Werner 2010). Expectations grow that women should earn income, increasing their responsibilities towards their families, a process Chant (2007) terms a 'feminisation of responsibility and/or obligation'.

Work's impacts on gender and age relations are socially and culturally embedded and therefore spatially and temporally uneven (Kabeer 2000). Studies suggest Filipino girls work to support parents (Lauby and Stark 1988), while those in Java work in defiance of parents (Wolf 1992). Mexican households reorganise to lighten factoryworkers' domestic work, but in the Philippines workingwomen's family responsibilities intensify (Chant 1996). Women in Istanbul's garment industry gained bargaining power at home and work, but when wage rose, firms relocated (Eraydin and Erendil 1999). The sector's volatility means gains are easily lost (Chant and McIlwaine 1995). 
Ansell N, Tsoeu-Ntokoane S and Hajdu F (in press and online) 'Women's changing domestic responsibilities in neoliberal Africa: a relational time-space analysis of Lesotho's garment industry' Gender, Place and Culture

While much research on the globalising garment industry has focused on female workers' personal experiences (within and beyond the factory), some studies have recognised its wider effects. While neo-liberal restructuring has increased demand for female labour, male unemployment has followed (Katzman 1992), arguably leaving men 'in crisis' (Sweetman 1997). Loss of economic role may reduce their authority in families and communities (Datta 2004). Some respond through gender-based violence (Green 2003); others undertake more domestic work (Cravey 1999). Factorywork may also prompt intra-familial conflicts relating to gender and age (Mills 1999).

While the effects of export-industry growth on workers' husbands and parents have been scrutinised, effects on children remain neglected. Kabeer (2000) briefly outlines garment workers' childcare arrangements, but not children's experiences. Globalisation is argued to be restructuring childhood and youth (Ruddick 2003), but fear of reinforcing Bowlby’s (1966/1951) discredited notion that women's employment harms children (see Waldfogel's 2002 review of evidence) has deterred research. Children are, however, affected by either parent's employment or unemployment, as impact studies of the economic crisis testify (Dornan 2010).

Industrialisation affects children through its impacts on social reproduction, both daily and generational (Katz 2001). Social reproduction serves society at large, including private sector employers, but is usually delivered by families (day-to-day care of the young, sick and elderly, food preparation, household maintenance; transmission of values, norms, skills and knowledge) and the state (formal childcare, education, healthcare and social welfare). While rural households subsidise low wages and cushion against unemployment (Kelly 2009), globally mobile export industries invest little in reproducing local labour supplies (Katz 2001). Moreover, 
Ansell N, Tsoeu-Ntokoane S and Hajdu F (in press and online) 'Women's changing domestic responsibilities in neoliberal Africa: a relational time-space analysis of Lesotho's garment industry' Gender, Place and Culture

neoliberal governments are also disinvesting from social reproduction leaving responsibility to the unpaid caring work of women (Steans and Tepe 2010), with problematic but underresearched consequences for both women and children.

Social reproduction encompasses not only childrearing, but also care of the elderly, sick and disabled. This, too, is usually undertaken by female kin, sometimes assisted by community networks and public providers. However, spatial dislocation and long hours of factorywork can sever workers' connections with families and friends (Green 2003), and casualised employment generates only temporary social networks (Carnoy 1999).

Since factories are spatially concentrated, garment-sector employment generally entails migration, complicating its social impacts. Where migrant workers leave families behind, gender and age relations are restructured across space, affecting household form, economics, decisionmaking and the organisation of productive and reproductive work (Lawson 1998; Silvey 2001), with economic, social and psychological consequences for adults and children in both households (Pribilsky 2001).

While some research has explored spatial dimensions of the restructuring associated with industrialisation, implications of the temporalities of factorywork have received minimal attention. However, as Ong (1987:10) points out, the synchronisation of local life with the rhythm of advanced capitalist societies challenges women 'as they enter into the world of labouring by the clock' and requires reworking of domestic relations. 
Ansell N, Tsoeu-Ntokoane S and Hajdu F (in press and online) 'Women's changing domestic responsibilities in neoliberal Africa: a relational time-space analysis of Lesotho's garment industry' Gender, Place and Culture

\section{Theoretical framework: relational time-space analysis}

In this article we examine how the time-space structuring of garment sector work articulates with that of wider society to construct new time-spaces that shape and constrain women's experiences, and reconstitute their relationships with those for whom they have caring responsibilities. To do so we draw on recent work theorising time-space in human geography (Massey 2005; Crang 2005; Dodgshon 2008). Viewed as socially constructed and relational, time and space are not neutral containers in which things happen, but rather produced through social processes: through happenings and relations between phenomena (Dodgshon 2008; Massey 2005). In turn, they shape social processes (Crang 2005). Both are multi-dimensional; dimensions of time, for instance, include duration, sequencing and frequency (Adam 2004). Implicit in this non-Cartesian view, space and time are also profoundly intertwined. Rather than treating them as analytically distinct, Massey (2005) argues that time and space must be thought together as 'time-spaces'. However, 'thinking of time and space together does not mean they are identical ..., rather it means that the imagination of one will have repercussions (not always followed through) for the imagination of the other and that space and time are implicated in each other' (Massey 2005:18).

Time-spaces are relationally constituted (Ellegård and Vilhelmson 2004),: they are not neutral but express and incorporate complex geometries of power relations (Panelli 2007). Timespaces emerge from varying circumstances (Mitchell 2008); they are fragmented and dynamic and the relationships that constitute them are organised and reorganised through networks, flows and mobilities (Ellegard and Vilhelmson 2004) of, for instance, ideas, information, wealth or 
Ansell N, Tsoeu-Ntokoane S and Hajdu F (in press and online) 'Women's changing domestic responsibilities in neoliberal Africa: a relational time-space analysis of Lesotho's garment industry' Gender, Place and Culture

people. Time-spaces are also scaled, spatially and temporally, encompassing short-lived events, longstanding long-distance relationships, regular local journeys or international migrations.

A time-space approach is valuable for examining factorywork's social impacts, juxtaposing financial effects against wider socio-material constraints. Effects on wellbeing reflect not simply the scale, distribution and meaning of financial rewards (Kabeer 2008) but also how the rigid and relatively bounded time-spaces of factorywork articulate with those of women's relationships with parents, spouses, children and others. Such relationships may, for instance, demand extensive travel to fulfil expectations relating to everyday needs and (spatiotemporally located) events (births, deaths, illnesses). Moreover, while income might expand women's opportunities and capacities to fulfil social obligations, time-spaces of both factory and family life impose financial costs and other constraints. These processes articulate to produce new time-spaces through which women fulfil altered social obligations, and some traditionally female roles are neglected. We use the term 'time-space structuring', to refer to how time-spaces constrain actions and enable new forms of social relation, in turn expressed in time and space.

\section{Lesotho's garment industry: growth, impacts and the African context}

Our research was undertaken in a region where the garment sector is relatively new, and its impacts underresearched. Here, the pre-existing socio-spatial relations differed from those pertaining in the Central American and Asian countries whose garment industries have received most attention. Sub-Saharan Africa was once shunned by manufacturers, viewed as politically unstable and lacking adequate infrastructure (Pearson 1998). While the manufacturing sector remains small, most African governments now embrace neoliberal arguments for boosting trade 
Ansell N, Tsoeu-Ntokoane S and Hajdu F (in press and online) 'Women's changing domestic responsibilities in neoliberal Africa: a relational time-space analysis of Lesotho's garment industry' Gender, Place and Culture

(Gibb 2003). This view underlies AGOA, which offers duty-free, quota-free access to US markets for (currently) 41 African countries willing to commit to neoliberal policies, covering $72 \%$ of Africa's exports. From 2001-2007, exports to the US from these countries almost trebled (Zappile 2011). Garment manufacture is particularly favoured: African clothing exports were growing before AGOA, but the removal of tariffs provoked an immediate $27 \%$ expansion in 2000/1 (Mattoo et al 2003).

The country with the sharpest garment sector growth is Lesotho (Seyoum 2007), now Africa's leading exporter of garments to the US. Preferential access to EU markets boosted inward investment in the 1990s, but AGOA stimulated more dramatic expansion. Lesotho's government has strategically exploited AGOA: its Poverty Reduction Strategy Article identifies unemployment as the main cause of poverty, and FDI in the garment sector as the best remedy (Kingdom of Lesotho 2006). Since the 1990s, Lesotho has advertised a relatively educated, compliant, low-waged workforce, favourable tax regime, access to foreign exchange and reasonable infrastructure (Salm et al 2002; UNDP 1998). Exporters also benefit from new banking and finance provisions (SADC 2004), and Lesotho's membership of the Southern African Customs Union and Common Monetary Area.

Growth has not been continuous and threats exist. Between 2000 and 2001 garment exports to the US increased from US\$140.2 million to US\$214.8 million (Mattoo et al 2003), the sector contributing 42.5\% of GNI (SADC 2004). Exports reached US\$456 million by 2004 but fell to US $\$ 281$ million by 2010 following the end of the MFA which liberalised quotas for competitors including China (agoa.info 2011). Today forty mainly Taiwanese-owned factories in Maseru (the capital city) and Maputsoe (80km northeast of Maseru,) employ 42,000 people 
Ansell N, Tsoeu-Ntokoane S and Hajdu F (in press and online) 'Women's changing domestic responsibilities in neoliberal Africa: a relational time-space analysis of Lesotho's garment industry' Gender, Place and Culture

(down from 60,000 at the peak), $88 \%$ of whom are women, most from poor rural households (Wallengren 2009; Kingdom of Lesotho 2006). The industry remains vulnerable to political instability or a strengthening Rand (Kingdom of Lesotho 2006).

Geographically, Lesotho is a mountainous enclave within South Africa. Most of its 1,880,661 inhabitants (KoL 2007) and all significant urban centres occupy the 'lowlands' in the west and north. Here, most towns and villages are connected by bus and minibus taxi services, with few more than a day's journey from Maseru, although the cost of transport ishigh. The 'foothills' are more sparsely settled, and only 10\% of Lesotho's population inhabit the 'highlands': three quarters of the country where many villages are accessible only on horseback or foot.

Socially and economically, Lesotho differs from regions with more established garment industries. Its rural areas have long functioned as 'labour reserves', apartheid South Africa favouring spatio-temporal separation of economic production and social reproduction. Until the early 1990s, South Africa's mines employed half Lesotho's adult men at any time, contributed half its GNP (UNDP 1998) and strongly conditioned relations of gender and generation (Gay 1980; Murray 1981). Male employment was subsidised by a rural 'subsistence' sphere inhabited by women, children, the sick and elderly, providing social reproduction and an agricultural safety net against unemployment (Murray 1981). Historically, social reproduction was undertaken by women and organised at household level, with minimal input from the state or employers, and limited involvement of informal self-help organisations (Ansell 2008). Whereas parts of Africa have long histories of young women migrating for work (see, for instance, Awumbila and Ardayfio-Schandorf 2008), this was rare in Lesotho. Female (or family) migration to South 
Ansell N, Tsoeu-Ntokoane S and Hajdu F (in press and online) 'Women's changing domestic responsibilities in neoliberal Africa: a relational time-space analysis of Lesotho's garment industry' Gender, Place and Culture

Africa was prohibited from the 1960s to the 1990s; a few defied this, but numbers of female migrants remained small (Crush et al 2010; Lefko-Everett 2007). Women without educational credentials had few opportunities within Lesotho. Moreover, given men's relatively high wages, women's reproductive role was valued over their financial contribution.

The gender relations associated with this situation are complex. Women in Lesotho were slow to gain political or economic rights (Epprecht 2000) and customary law treats them as perpetual minors (Mapetla and Sakoane-Songca 2005). Patriarchal gender (and generational) relations remain rigidly enforced through bridewealth payments, and young brides join their inlaws' households as 'makoti' (new wives), expected to work hard caring for husbands, children and extended families and not to seek work elsewhere (Hajdu et al 2011). However, men's regular absences left women influential in both household and public spheres (arguably why their formal rights were curtailed (Epprecht 2000)). Moreover, because boys were needed to herd cattle and men's employment required little education, girls have historically received more education than boys. Interestingly, UNDP (2012) ranks Lesotho only $108^{\text {th }}$ of 146 nations in terms of gender equality, whereas the World Economic Forum places it $9^{\text {th }}$ of 135 , scoring joint first on indices of Educational Attainment and Health and Survival and second on Economic Participation and Opportunity (Hausmann et al 2011).

As the garment industry established itself, men's access to work was already declining. Mine employment fell from 100,000 in 1990 to 46,000 in 2006 (Crush et al 2010). Structural unemployment of 35-40\% (UNDP 1998) and associated family hardships prompted many women to migrate for work, despite family attitudes. Growing numbers engage in domestic and seasonal farmwork in neighbouring South Africa (Ulicki and Crush 2007), but many more enter 
Ansell N, Tsoeu-Ntokoane S and Hajdu F (in press and online) 'Women's changing domestic responsibilities in neoliberal Africa: a relational time-space analysis of Lesotho's garment industry' Gender, Place and Culture

Lesotho’s factories (Crush et al 2010; Dyer 2001; Kimane and Ntimo-Makara 1998).

Factorywork is not, however, commensurate with minework: wages are seven times lower; no subsidised food or accommodation is provided and there is no mechanism for remitting cash to rural areas (Crush et al 2010). Although classified by the World Bank as a 'middle income' country, in terms of human development Lesotho has slipped below both African and 'low human development' averages since 2002 (UNDP 2012).

The decision to work in a factory generally reflects material hardship. Southern African women migrate for more varied (social, economic and reproductive) reasons than men, and other parties - particularly husbands - are often involved in the decision (Dodson 1998). Usually, female migration is a survival strategy driven by household need, although sometimes in defiance of family dictates (Lefko-Everett 2007). Indeed, many young women see an independent income as an alternative to marriage, especially given male unemployment levels (Hajdu et al 2011). While factorywork pays less than most formal sector employment (the minimum wage is $£ 2.59$ a day, compared with $£ 3.18$ for retail work or $£ 3.11$ in the hospitality sector (GoL 2012)), it is more accessible, requiring fewer educational qualifications. It is also much better paid than most informal employment; rural domestic work, for instance, pays around $£ 12.40$ a month, notwithstanding higher urban living costs. Obtaining factorywork is highly competitive. Many women queue daily at factory gates for casual work. Regular work may take months or years to secure.

Lesotho's garment sector also confronts an alarming AIDS pandemic with HIVprevalence approximately $23.6 \%$ among adults (UNAIDS 2010) and $41.0 \%$ among factoryworkers (Wallengren 2009), imposing on employers costs of benefits, absenteeism and 
Ansell N, Tsoeu-Ntokoane S and Hajdu F (in press and online) 'Women's changing domestic responsibilities in neoliberal Africa: a relational time-space analysis of Lesotho's garment industry' Gender, Place and Culture

retraining (Carmody 2002). AIDS is impoverishing workers' households and communities and reshaping relations of gender and generation (Kimane and Mohale 2007). Where rural households lack healthy adults, productive and reproductive work increasingly falls to children and elderly people (Ansell and van Blerk 2004). While grandparents were always involved in childcare (through both patrilocal convention and maternal grandparents' 'ownership' of a woman's first child), grandparents' involvement is increasing (Kimane and Mohale 2007). AIDS also prompts migration: people return to villages to convalesce, widows are ejected from inlaws' homes and orphans move to relatives' homes (Crush et al 2010; Young and Ansell 2003). Garment sector growth is affecting people's capacity to address this pandemic.

\section{Research design}

To explore how garment sector work affects female factoryworkers and their families, the second author and two research assistants, all Sesotho-speaking Lesotho-nationals, undertook research in and around Maseru, where many factories are located. The team visited various neighbourhoods (Seapoint, Stadium, Thibella, Ha Leqele, Ha Thamae) and one small town (Ha Motloheloa, $30 \mathrm{~km}$ from Maseru's factories) and used purposive snowball sampling to identify participants from diverse factories who were broadly representative of the workforce demographically and socially. Both permanent and casual workers with wide-ranging job types were included. A questionnaire was used initially to elicit information concerning 42 workers' households, focusing on (changing) household structures; resources and sources of income; and significant recent events including illness and deaths. To explore the impacts of factorywork on differentlypositioned individuals, and changing intra-household relations, semi-structured interviews were 
Ansell N, Tsoeu-Ntokoane S and Hajdu F (in press and online) 'Women's changing domestic responsibilities in neoliberal Africa: a relational time-space analysis of Lesotho's garment industry' Gender, Place and Culture

then conducted with all resident members of these households who were available and willing to participate. Participants comprised 40 factoryworkers, six workers' husbands, 17 of their children (aged 7-21) and nine other household members (including a mother, sister, cousin, niece, friend and housekeeper). Additional questionnaires were administered to five 'source' households in the mountain village of Ha Rantelali. Members of three of these households were interviewed by the third author, assisted by a local research assistant. All interviews were conducted in workers' homes in Sesotho, recorded, transcribed and translated. The data were analysed thematically, using NVivo software.

To contextualise our qualitative research, the findings of a recent large-scale survey are useful (Wallengren 2009). Unlike our research, this targeted both male and female factoryworkers, primarily those on permanent contracts. Of the sample of $2792,88 \%$ were women, the average age was 31 and $63 \%$ had migrated from their family homes $(71 \%$ of which were rural). $62 \%$ visited their family home at least monthly. $58 \%$ were married and of those married or in long-term relationships, $66 \%$ lived with their partner. Of those not resident with their partner, $75 \%$ saw them monthly. $11 \%$ were widowed. The average number of biological children was 1.6 , but workers were typically financially responsible for 2.2 children. $45 \%$ were sole breadwinners. Of the 40 workers we interviewed, whose average age was 32 , nearly half were currently married, of whom about three-quarters lived with their husbands. Nine were widowed. Around half had children living with them, while 15 had children resident elsewhere, usually cared for by a grandmother or paid helper. Twenty-five lived in one-room rented homes, a few rented larger properties and nine lived in houses they or their families owned. 
Ansell N, Tsoeu-Ntokoane S and Hajdu F (in press and online) 'Women's changing domestic responsibilities in neoliberal Africa: a relational time-space analysis of Lesotho's garment industry' Gender, Place and Culture

Our discussion focuses on how financial and spatio-temporal aspects of factory employment articulate to challenge and transform women's domestic responsibilities. We begin by briefly outlining the financial impacts, then explore the time-spaces of factorywork and finally the implications of this time-space structuring for women's relationships with and responsibilities towards their children, sick relatives and rural households.

\section{The financial impacts of garment factorywork}

The paramount reason women engage in factorywork is to earn an income, and the impact of their work is strongly associated with that income. As noted above, wages are low, and those with skills or qualifications to find better paid employment endeavour to do so. However, as Bastia (2007) observed in Argentina, many women have little choice but to work in garment factories. Asked how it would be if she lost her job, 'Mamonate remarked:

Let me tell you, my life is very backward even though I am working. I can't imagine how it would be if I wasn't.

Factorywork's impacts elsewhere vary with life course stages and differing domestic responsibilities (Kabeer 2008; Lawson 1998). In Lesotho, some young women without dependents mentioned being able to buy themselves clothes or furniture, while others, like Sefabatho, a single, childless 29-year-old, declared: 
Ansell N, Tsoeu-Ntokoane S and Hajdu F (in press and online) 'Women's changing domestic responsibilities in neoliberal Africa: a relational time-space analysis of Lesotho's garment industry' Gender, Place and Culture

For me it's the same as staying at home and doing nothing. I don't see any difference.

Sometimes I even think of leaving and going back home ... I'm not satisfied. I am working in Maseru but I have nothing to show that I am working. ${ }^{l}$

For most women, however, the decision to work took place in the context of wider relationships. Crush et al (2010) found that Basotho women migrating for work in South Africa did so because their households depended on them for survival. Similarly, many factoryworkers have dependent children and some younger women were providing for orphaned siblings and nieces/nephews. Their needs were the spur to find and continue in work. As Mafusi explained:

When I stay at home I can't satisfy my children's needs but when I work I can see, I try to help.

Women with children focused on how their incomes, however small, enabled their families to eat and their children to attend school. Most were very conscious of the difference their wages made across a range of relationships. Matlali, whose children were resident elsewhere, claimed:

[Without this salary] life would be very hard. I would depend on those people who are not working and depend on me now. We would all suffer.

Widows, in particular, remarked on finding their salaries inadequate following their husbands' deaths. 
Ansell N, Tsoeu-Ntokoane S and Hajdu F (in press and online) 'Women's changing domestic responsibilities in neoliberal Africa: a relational time-space analysis of Lesotho's garment industry' Gender, Place and Culture

From children's perspectives, too, paying for food and often school fees were viewed as the primary benefits of their mother's or guardian's work. 14-year-old Lerato observed that since her aunt started working at the factories,

She buys me clothes, sends me to school and also buys my lunch box.

When asked about the effects of factorywork, children spoke exclusively of the material benefits, and most viewed their mother's or guardian's work positively.

Women's need to work also reflects (relationships that provide access to) alternative income sources. As in the research reported by Crush et al (2010), most women had no other source of household income. 14 of the 21 married women's husbands provided some cash, although their work was often insecure. Like the children, husbands evaluated their wives' employment in almost exclusively financial terms. Husbands, however, were less positive about the value of the work than either women or children. Like Khura (below), most began by asserting that women's earnings were so meagre that the impact was negligible; however, when pushed further, almost all acknowledged some reliance on their wives' incomes.

I -How does her work affect your lives?

$\mathrm{K}$ - She is working but we don't see what she is working for, because there is little money and there are plenty of needs for my parents' home and my own family.

I - If she was not working how would your life be?

$\mathrm{K}$ - It would be harder than it is right now.

The tendency to downplay their wives' contributions may reflect not only low salaries but a reluctance to accept women as breadwinners (ironically, Khura also worked in a factory, 
Ansell N, Tsoeu-Ntokoane S and Hajdu F (in press and online) 'Women's changing domestic responsibilities in neoliberal Africa: a relational time-space analysis of Lesotho's garment industry' Gender, Place and Culture

presumably on low wages). Conversely, the focus on monetary aspects suggests women's other roles are invisible or held in low esteem.

\section{Time-spaces of garment factorywork}

While most household members focused exclusively on women's wages, women themselves spoke of other impacts of work on their lives, most of which related to the spatio-temporal structuring of the work and its implications for their capacity to fulfil other socially-expected roles. Time-spaces of factorywork intersect with those associated with living, usually as a migrant, in urban Lesotho, and of wider routines and events. We consider these time-spaces below, before discussing their implications for women's domestic responsibilities. Time-spaces of factorywork are characterised by relative boundedness and persistent regularity. Work takes place in spatio-temporally fixed and bounded locales that segregate workers from non-workers, with a regular rhythm and little opportunity to break from routine. These features profoundly shape its social impacts.

Employees are confined within the factories from 7am to 5pm, five days a week. Many undertake paid overtime for another hour or more (11 hours a week are permitted); some complained their employers required this.

I start work at 7 and leave at $6 \mathrm{pm}$, which is overtime, [but if you leave] before that, you get in trouble.

(Malifomo)

The long hours, coupled with other duties, proved exhausting: 
Ansell N, Tsoeu-Ntokoane S and Hajdu F (in press and online) 'Women's changing domestic responsibilities in neoliberal Africa: a relational time-space analysis of Lesotho's garment industry' Gender, Place and Culture

We work so hard to the extent that when you get home you are so tired you can't do anything.

(Thato)

The problem is not enough sleep; I suffer due to lack of sleep. In the evening when I arrive from work I have to cook. When I finish cooking I get into washing clothes. Then in the morning at 4, I am already up, I rinse and hang the washing on the line. I leave having made sure that I have swept the stoep ${ }^{2}$ and prepared everything.

('Malipina)

Thus the time-spaces of factorywork negatively affect women's wellbeing and relationships by depriving them of energy and sufficient sleep.

The time-space of work, however, extends beyond the factory, articulating with wider social and economic contexts. Housing in Maseru is expensive, especially around the factories. A single room costs $£ 9.30$ (with electricity $£ 15.50$ ) from their $£ 48$ monthly earnings. Thus many women live further away and commute. Matello, for instance, leaves home at 5.30am returning at 8pm. Transport is costly: each minibus taxi journey in or around Maseru costs $30 \mathrm{p}$, and since many workers change taxis centrally, they pay $£ 1.20$ daily. Those who stay alone in Maseru (having fewer domestic pressures on their time) therefore often walk to work, exacerbating the exhaustion. M'atlotliso walks 1.5 hours twice daily. Several women interviewed in Ha Motloheloa had avoided moving to Maseru to save the cost and disruption to their families and spent even longer travelling. Manthabiseng was equivocal: 
Ansell N, Tsoeu-Ntokoane S and Hajdu F (in press and online) 'Women's changing domestic responsibilities in neoliberal Africa: a relational time-space analysis of Lesotho's garment industry' Gender, Place and Culture

Right now transport is killing me; at the same time, if I go and stay in Maseru I will be working for two families [ie two households to look after].

Beyond the long hours of work and travel, employers strictly regulated women's health/familyrelated absences from work, extending the factory's spatio-temporal influence. Migrant women often needed to travel to respond to domestic crises in far places entailing multi-day absences. In such circumstances, employers required letters from doctors or chiefs, to substantiate the crisis claimed.

If I have to go somewhere I've got to have something that shows I went there ... Even if I have a funeral, I have to bring the mortuary letter or the chief's letter.

(Likhapha)

Such absences were enforced not only through bureaucratic regulation, but also economic sanctions:

When you go for a funeral, maybe you have to leave at least on Thursday [funerals are usually on Saturdays], so those two days I won't get paid. If it is a very close relative who died, and I have to be there for all the funeral arrangements, I will ask for a week and that week will not be paid.

(Mamfundo)

Due to AIDS, funerals are frequent. The dissonance between time-spaces of factorywork, as imposed by employers, and time-spaces of social obligation challenges women's capacities to fulfil their families' expectations. 
Ansell N, Tsoeu-Ntokoane S and Hajdu F (in press and online) 'Women's changing domestic responsibilities in neoliberal Africa: a relational time-space analysis of Lesotho's garment industry' Gender, Place and Culture

In summary, factorywork radically affects the spatio-temporal organisation of women's lives, requiring them to be in particular places at particular times and for long durations. Employers strictly manage the time-spaces of women's lives, even beyond the physical confines of the factory. Spatio-temporal and economic aspects are co-produced: in negotiating divergent time-spaces, some women partially sacrifice their modest financial gains to mitigate inconvenience, exhaustion and incapacity to fulfil obligations. While parents, husbands and inlaws have long sought to control Basotho women's time and mobility, the intensity of regulation of their urban lives differs markedly. While they gain some freedom from patriarchal family control by living (often alone) in town, they have minimal 'free' time to use as they wish. Only by careful management of time and movement can women negotiate the pressures on their lives of both work and spatially extended domestic responsibilities.

\section{Implications of the time-space structuring of garment factorywork}

We now consider the effects of this time-space structuring on women's relationships with those toward whom they have obligations of care: their children, sick relatives and rural households.

\section{Children}

As indicated above, many factoryworkers had dependent children whose wellbeing motivated their employment. However, while women sought to support their children financially, their daytime absence curtailed their capacity to provide more practical care and supervision. Most lived in Maseru without a partner: nearly a quarter had children staying with them, but no other adult who could supervise the children while they worked. Another quarter managed the contradiction between factory and care demands through a spatio-temporal strategy of leaving 
Ansell N, Tsoeu-Ntokoane S and Hajdu F (in press and online) 'Women's changing domestic responsibilities in neoliberal Africa: a relational time-space analysis of Lesotho's garment industry' Gender, Place and Culture

their children 'at home' (in the village) with their husbands or parents and making periodic visits. For some, this imposed significant emotional costs.

I - Has your staying in Maseru affected the lives of your children in Mohale's Hoek (a district $140 \mathrm{~km}$ from Maseru)?

$\mathrm{R}$ - Because I'm not always with her, it's not pleasant. I miss her. It is even worse now that the bus fare has gone up. I miss them all the time and I cannot go regularly.

(Sebabatso)

Even where both parents stayed in Maseru, they sometimes decided to leave their children with grandparents. Morena, one factoryworker's husband who relied on casual work, explained how they dealt with their inability to support their four-year-old daughter:

Truly, even considering [my wife's] help, I am also struggling. That's why the child is at her home (maternal grandmother's).

(Morena)

The spatio-temporal separation of families brought about by factorywork (particularly its long hours) has to some degree redefined women's relationships with their children and also wider family relationships. Although separation between mothers and children is not new, historically children, more often than their mothers, moved away (Murray 1981). Because the process today counters cultural expectations, it is particularly challenging for women.

When asked how employment affected their capacity to care for children, most women referred to financial responsibility ahead of other duties. Even discharging their financial obligations required the negotiation of time-space constraints. Most took money when they 
Ansell N, Tsoeu-Ntokoane S and Hajdu F (in press and online) 'Women's changing domestic responsibilities in neoliberal Africa: a relational time-space analysis of Lesotho's garment industry' Gender, Place and Culture

visited their families, but unanticipated financial needs arose that were frustrating to address from a distance, as Thato explained:

You cannot always find solutions for your problems. One time you will get a message from home that your child has no shoes and you will find that it takes time [to provide them] or in the end you don't get them at all.

Rather than moving to Maseru, some women commuted from nearby towns to avoid leaving their children, partly to ensure adequate supervision:

[If I moved to Maseru], I would have to leave my children alone and they would have no one to look after them.

(Mamothepa)

Such arrangements may also reflect financial priorities, where commuting costs less than establishing a second household, as Matello's comments reveal:

It would be hard [to move to Maseru] because I would leave my children alone, and my money would lessen.

Some women who did move to Maseru kept their children with them. Several employed childminders, or had relatives available. Those with school-children aged over 10 usually left them unsupervised for the four or five hours between school and their mother's return from work.

He remains alone when he comes back from school, playing with other children. 
Ansell N, Tsoeu-Ntokoane S and Hajdu F (in press and online) 'Women's changing domestic responsibilities in neoliberal Africa: a relational time-space analysis of Lesotho's garment industry' Gender, Place and Culture

The first two play at my home after school and the small one I leave with my neighbour

('Malipotso)

Some family members were aware of the time-space constraints factorywork posed. 14-year-old Tebello, for instance, complained her mother was often late, as she had to 'make the score', meaning working in her own time to complete the day's work allocation. Most husbands were preoccupied with material impacts, but Palesa's husband suggested ways to improve factory conditions:

Firstly they should have salary increase, secondly they should work reasonable hours like from 8 to 4.30 and lastly they should get enough money to improve the lives of their families.

The time-spaces of garment sector work thus challenge women's relationships with their children. Wages enable most to provide children's basic care (education, food and clothing) and they and their families rationalise their employment on this basis. However, time-space structuring of work undermines women's other culturally defined responsibilities towards children - providing supervision, practical care, social and emotional support. Many downplay these non-material obligations, or confer them on others such as grandmothers or paid helpers. Most employ explicitly spatio-temporal strategies to fulfil expectations: they reside with relatives; send children elsewhere; identify strategies for supervision, for visiting and delivering financial remittances. Potentially, then, garment sector work is rewriting maternal responsibility, as women adopt the financial provider role historically associated with fatherhood. However, rather than a reallocation of maternal roles to fathers, other women (older, more impoverished) 
Ansell N, Tsoeu-Ntokoane S and Hajdu F (in press and online) 'Women's changing domestic responsibilities in neoliberal Africa: a relational time-space analysis of Lesotho's garment industry' Gender, Place and Culture

step in, mirroring processes in the global North (Holloway 1998), and reflecting the widespread 'feminisation of responsibility' highlighted by Chant (2007).

\section{Sick relatives}

Given the high AIDS prevalence, numerous respondents had responsibility towards sick family members. Some took time off to take relatives to visit doctors or the hospital, despite this causing problems at work. The spatio-temporal separation of kin entailed in factorywork often restricted caring for relatives, like caring for children, to financial assistance. Sefabatho, for instance, sent money home to enable her brother with TB to eat well, while Matumelo had hired someone to care for her father-in-law. These women's salaries, however small, enabled them to care in this way, which they considered as significant as providing practical help.

Constraints of time and distance also limited women's financial assistance of distant relatives . Despite the growing prevalence of mobile phones, communication with rural households remains difficult, as Lineo recounted:

Sometimes when someone is sick, you only get to hear about it after they've died, because they have no means to get to Maseru, or I won't know unless I go home.

While most women offered only financial assistance, some had to provide practical care. This itself had a financial cost, as women had to take unpaid leave, or forego opportunities for casual work. Malehana, whose HIV-positive husband had irregular security work, complained:

My husband is my biggest problem, like now, now he went away after Christmas leaving me with his sick mother and the children ... The biggest problem is I'm still working in the 
Ansell N, Tsoeu-Ntokoane S and Hajdu F (in press and online) 'Women's changing domestic responsibilities in neoliberal Africa: a relational time-space analysis of Lesotho's garment industry' Gender, Place and Culture

factories, but right now I'm staying at home, looking after my mother-in-law because she cannot remain by herself.

While women's salaries helped them assist with their families' healthcare costs, space-time constraints rendered more practical forms of care problematic. Where factorywork and care were incompatible women were forced into difficult decisions. The burden of care was either left to others (with unknown consequences) or women had to abandon their employment, at least temporarily. Despite women adopting responsibility for earning money, there has been no apparent counter-shift in the responsibilities assumed by men. Even where husbands experience fewer time-space constraints, they expect their wives to fulfil practical caring roles, again reflecting Chant's (2007) 'feminisation of responsibility'.

\section{Rural households}

Most women had rural families - their parents or, in the case of married women, husbands and in-laws. As mentioned above, many women left their children with these households to be cared for, and some were supporting sick relatives 'at home'. Several women commented that their families did not want them to leave home to seek factorywork.

I made the decision alone, because my husband was unsatisfied. At the time when he realises that things are getting tough, only then will he agree, and when I have to go, he refuses to let me come and work in the factories. So I told him I'm in Maseru and I'm working.

('Malipina) 
Ansell N, Tsoeu-Ntokoane S and Hajdu F (in press and online) 'Women's changing domestic responsibilities in neoliberal Africa: a relational time-space analysis of Lesotho's garment industry' Gender, Place and Culture

This attitude related partly to (often parental) concerns about young women's wellbeing when living alone, but also a belief that women should care in practical ways for their families, and children in particular. Mabataung, who returns home every four months, described how her absence affects her relationship with her family, who feel she should be performing duties in their home:

It is not good because you will find that there are needs that I am supposed to meet at home and I am not able to do them because I am here in Maseru.

A long history of male labour migration and almost exclusive female responsibility for domestic and agricultural spheres has coloured perceptions of appropriate gender roles (Murray 1981). Unemployed men are usually considered incapable of performing traditionally female roles (Ansell 2002); women resent their failure to contribute to household wellbeing but still feel obliged to fulfil such roles themselves:

I -What would happen in Ha Rantelali if most of the women were working in the factory and the men were at home?

$\mathrm{R}$ - The children would starve, food production in the fields would be low, men are very useless.

(Nthabiseng, wife of a migrant factoryworker) Nonetheless, it was usually the financial contribution that family members referred to when asked how a woman's factorywork affected them and their families. Most women contributed roughly $£ 12.40$ from their $£ 48$ monthly pay. Others gave no money, but took goods when they visited. For both young single women and those more mature, assisting their families was 
Ansell N, Tsoeu-Ntokoane S and Hajdu F (in press and online) 'Women's changing domestic responsibilities in neoliberal Africa: a relational time-space analysis of Lesotho's garment industry' Gender, Place and Culture

commonly a key motivation for working. Sebabatso spoke of 'seeing to it that those people at home eat well', while Clare explained:

At times you will find I have to help the family, maybe by buying maize meal, because my father is no longer working but he still goes to RSA [South Africa] to claim his money, so I give him the bus fare.

Rather than merely substituting financial for practical contributions, some women paid others to undertake some of their family responsibilities, using their wages to overcome spatio-temporal distance. Lineo told us:

It affects familial obligations because when the fields need hoeing, I have to take out money from my factorywork so that they can hoe. I could do that work myself.

The frequency of visits to rural households varied from fortnightly to once or twice a year, most returning every month or two. Women also visited at holiday times and for funerals. Many only went home when they had money or gifts to take. One woman sometimes sent her son, as the transport was cheaper:

... every month, I go home or I send them money. If I'm unable to go, I send my boy. He is now older and his bus fare is a little less than mine.

('Mamonate)

Infrequent visits may reflect women's limited capacity to contribute financially, as incomes are low and sometimes sporadic: economic factors and spatio-temporal outcomes of factorywork are intensely entwined. 
Ansell N, Tsoeu-Ntokoane S and Hajdu F (in press and online) 'Women's changing domestic responsibilities in neoliberal Africa: a relational time-space analysis of Lesotho's garment industry' Gender, Place and Culture

Among the Ha Rantelali households, historically accustomed to more generous mine wages, some complained they received too little money to cover even the raising of grandchildren left in their care. Asked whether her family's lives had changed due to her daughter's factorywork, one mother replied:

No truly, we don't see any difference; I am carrying the burden of her child.

It may be that families resent young women moving away, particularly when left to care for children, and therefore downplay the value of remittances. Equally, factoryworkers may themselves overstate the significance of their contributions to justify their absence from home. Overall, work in the factories enabled most women to provide some financial or other material support to their distant families, and most maintained regular, if infrequent, contact. However, as with other areas of responsibility, the time-space structuring of familial relationships caused women very real difficulties, and left certain obligations unfulfilled.

\section{Conclusions}

As Kabeer (2008:96) has noted, 'the expansion of economic opportunities for women has been a powerful force for change under many different circumstances'. In Lesotho, garment factorywork is transforming the time-space configuration of the lives of many women, and the society they belong to, from that which pertained in the past, when men migrated to mines in South Africa leaving women at home, rearing children and caring for the sick and elderly, providing practical, social and emotional support and growing crops for household consumption. Constructed through, and shaping, social change (Mitchell 2008), new time-spaces are built upon 
Ansell N, Tsoeu-Ntokoane S and Hajdu F (in press and online) 'Women's changing domestic responsibilities in neoliberal Africa: a relational time-space analysis of Lesotho's garment industry' Gender, Place and Culture

and transform the old. Constraining workingwomen through long hours of work, long distances from home, expensive, time-consuming travel and complex, rigid procedures for securing a break from daily routine, factorywork strongly shapes the lives of workers and their kin. The new time-spaces reflect and constitute the emergence of new power relations (Massey 2005, Panelli 2007): they serve the interests of a globally mobile industry but reframe women's relationships with their families, affecting how they can discharge conventional responsibilities for social reproduction. Through changing everyday routines, long-term and wider social processes are transformed.

It is noteworthy that, despite the evident challenges to women's domestic responsibilities posed by the time-spaces of factorywork, when asked to identify their most pressing problem most women pointed to their low wages. Without male employment opportunities, women in Lesotho must provide economically for their children, the sick and their rural families. Women are increasingly viewed, by themselves and their families, as breadwinners. As 36-year-old widow, Matlelima, pointed out, 'everything is money'. However, the significance of money in this neoliberal economy is partly attributable to the time-space structuring of women's lives. Women's responsibilities for social reproduction (for children's education, care of the sick and elderly) have not vanished but, given the time-space constraints of factorywork, these are increasingly discharged financially. This commodification of domestic roles echoes the situation in contemporary Western societies, where (particularly middle-class) women fulfil childcare and elder care responsibilities by paying other, lower status women (Cox 2006).

Elson (1999) long ago pointed out that workingwomen retain their domestic responsibilities. Chant (2007) argues further that they gain additional responsibilities: a 
Ansell N, Tsoeu-Ntokoane S and Hajdu F (in press and online) 'Women's changing domestic responsibilities in neoliberal Africa: a relational time-space analysis of Lesotho's garment industry' Gender, Place and Culture

'feminisation of responsibility/obligation'. However, in Lesotho, the time-space constraints of factorywork may preclude workingwomen from undertaking the more practical and emotional aspects of social reproduction, and even aspects that are readily commodified may remain unfulfilled where wages are low. Responsibility for these roles has not been assumed by the state or employer-provision of child or elder care: indeed, neoliberal pressures encourage

disinvestment from such services. Neither have men taken a larger share, even where their timespace constraints are diminishing. Sometimes, as in Western societies (Ansell and Smith 2009) and elsewhere in the Global South (Chant 2007), tasks are transferred to older women. At other times they remain unfulfilled. Thus garment factorywork, while providing income, impacts detrimentally not only on women but on children, the sick and the elderly.

The role of men, specifically husbands, merits further consideration. Lawson (1998:42) has argued that in order to understand the impacts of work-related mobility, we 'need to understand how domestic divisions of labour are produced and maintained', recognising that 'paid and unpaid contributions of male and female household members are valued differently within the domestic sphere'. Men in Lesotho dismiss women's factorywork as trivial, being much lower paid than mining or other male occupations. This doubtless causes problems for families shifting from a male to a female breadwinner. However, in this context, where few men are employed and many women widowed, women's incomes are crucial for sustaining themselves and their families. Yet men have shown little readiness to take on social reproduction.

The findings reported here raise serious questions concerning the neoliberal anti-poverty strategies adopted by Lesotho and many other countries. In a context of high male 
Ansell N, Tsoeu-Ntokoane S and Hajdu F (in press and online) 'Women's changing domestic responsibilities in neoliberal Africa: a relational time-space analysis of Lesotho's garment industry' Gender, Place and Culture

unemployment, low-paid export sector jobs assist women to address, albeit inadequately, their families' material needs. However, when poverty is understood in wider terms, it becomes apparent that aspects of social reproduction required to secure the wellbeing of children, the sick and the elderly will go unfulfilled unless, alongside industrialisation, gender roles are significantly reworked or the state or capital adopt measures to facilitate social reproduction. Employers might, for instance, assist women to fulfil these roles through shorter working hours, more generous leave entitlements, housing provision, support for or direct provision of childcare and higher pay. Equally, social provision of care for children and the elderly might offer partial solutions. However, given that mobile export firms have little incentive to invest in social reproduction, and national governments fear the consequences of regulating and lack tax receipts or other income sources to fund a welfare state, such measures are unlikely to be taken without considerable external pressure. There are clearly roles here for trades unions and international campaigning organisations. In the absence of significant change, spatio-temporal aspects of factorywork, combined with inadequate pay, seriously diminish industry's potential to address poverty.

\section{Acknowledgements}

Funding for this project was provided by Brunel University. We are grateful to our research assistants, Tsepang Thaanyane, Maseqobela Mohale and Tsoana Molauli who helped conduct the interviews; Likeleli Mariabene who transcribed and translated the recordings; and to all those who were interviewed for this research. We would also like to thank the anonymous referees for their insightful suggestions. 
Ansell N, Tsoeu-Ntokoane S and Hajdu F (in press and online) 'Women's changing domestic responsibilities in neoliberal Africa: a relational time-space analysis of Lesotho's garment industry' Gender, Place and Culture

\section{Notes}

1. Emphasis on low wages may reflect the paucity of opportunities to make such concerns heard.

2. Stoep is Afrikaans for a porch or set of steps at the entrance to a house.

\section{Notes on Contributors}

Nicola Ansell is a Reader in Human Geography at Brunel University, London. Her research interests focus on the impacts of social and cultural change in the lives of young people in southern Africa. Specific research projects have looked at the impacts of AIDS on young people's migration; the ways in which education sectors are adjusting to the needs of AIDS-affected young people; the impacts of AIDS on young people's current livelihoods and future food security; and the impacts of Lesotho's garment industry. She has authored a book on Children, youth and development (Routledge 2005) and runs an MA programme on Children, Youth and International Development.

Seroala Tsoeu-Ntokoane teaches at the Department of Political and Administrative Studies, National University of Lesotho. She earned her MA at the School of Politics, University of Kwazulu Natal and is a Doctoral student at Department of Politics, University of Johannesburg. She has conducted research in various areas including local government service delivery, local economic development, telecom regulation, the garment industry, food aid programmes, political constitutionalism and African parliaments. She is currently researching policy options for youth unemployment in Lesotho.

Flora Hajdu is a Postdoctoral Research Fellow at the Department for Urban and Rural Development, Swedish University of Agricultural Sciences. With a background in Geography and Anthropology, Flora Hajdu did her $\mathrm{PhD}$ on rural livelihoods in South Africa. Her postdoctoral research has focused on livelihoods, discourse and policy in South Africa, Lesotho, Malawi, Tanzania and Uganda. Her current research projects focus on the effects of large scale agro-investments on local livelihoods in Tanzania and the discourse surrounding climate compensation-related afforestation projects in Uganda.

\section{References}

Adam B 2004 Time Polity Press, Cambridge

AGOA.info 2011 'African Growth and Opportunity Act' Trade Law Centre for Southern Africa http://www.agoa.info/ accessed $22^{\text {nd }}$ March 2011 
Ansell N, Tsoeu-Ntokoane S and Hajdu F (in press and online) 'Women's changing domestic responsibilities in neoliberal Africa: a relational time-space analysis of Lesotho's garment industry' Gender, Place and Culture

Amin S, Diamond I, Naved RT and Newby M 1998 'Transition to adulthood of female garmentfactoryworkers in Bangladesh' Studies in Family Planning 29(2) 185-200

Amin S 2001 'Africa: living on the fringe?' Africa Insight 31, 3-7

Ansell N 2002 “'Of course we must be equal, but ...': imagining gendered futures in two rural

Southern African secondary schools' Geoforum 33(2) 179-194

Ansell N 2008 'Substituting for families? Schools and social reproduction in AIDS-affected

Lesotho’ Antipode 40(5) 802-824

Ansell N and Smith F 2009 'Young people, care and welfare' in Smith S, Marston S, Pain R and Jones J-P Handbook of Social Geographies Sage, London

Ansell N and van Blerk L 2004 'Children's migration as a household/family strategy: coping with AIDS in Malawi and Lesotho' Journal of Southern African Studies 30(3)

Awumbila M and Ardayfio-Schandorf E 2008 'Gendered poverty, migration and livelihood strategies of female porters in Accra, Ghana' Norwegian Journal of Geography, 62(3) $171-179$

Bandy J 2000 'Bordering the future: resisting neoliberalism in the borderlands' Critical Sociology 26(3), 232-267

Bastia T 2007 'From mining to garment workshops: Bolivian migrants in Buenos Aires' Journal of Ethnic and Migration Studies 33(4) 655-669Boserup E 1970 Women's role in economic development St Martin's Press, New York

Bowlby J 1966/1951 Maternal care and mental health Schocken, New York

Carmody P 2002 'Between globalisation and (post)Apartheid: the political economy of restructuring in South Africa' Journal of Southern African Studies 28(2), 255-275

Carnoy M 1999 'The family, flexible work and social cohesion at risk' International Labour Review 138(4)

Chant S 1996 'Women's roles in recession and economic restructuring in Mexico and the Philippines' Geoforum 27(3), 297-327 
Ansell N, Tsoeu-Ntokoane S and Hajdu F (in press and online) 'Women's changing domestic responsibilities in neoliberal Africa: a relational time-space analysis of Lesotho's garment industry' Gender, Place and Culture

Chant S 2007 Gender, generation and poverty: exploring the 'feminisation of poverty' in Africa, Asia and Latin America Edward Elgar, Cheltenham

Chant S and McIlwaine C 1995 'Gender and export manufacturing in the Philippines: continuity of change in female employment? The case of the Mactan Export Processing Zone' Gender, Place and Culture 2(2), 147-176

Cox R 2006 The servant problem: domestic employment in a global economy IBTauris

Crang M 2005 'Time space' in Cloke P and Johnston R (eds) Spaces of geographical thought: deconstructing human geography's binaries Sage, London pp 199-217

Cravey A J 1999 Women and work in Mexico's maquiladoras Rowman and Littlefield, Lanham MD

Crinis V 2010 'Sweat or no sweat: Foreign workers in the garment industry in Malaysia' Journal of Contemporary Asia 40(4) 589-611

Crush J, Dodson B, Gay J, Green T and Leduka C 2010 Migration, remittances and 'development' in Lesotho, Southern African Migration Programme, Idasa, Cape Town

Datta K 2004 'A coming of age? Re-conceptualising gender and development in urban Botswana' Journal of Southern African Studies 30(2), 251-269

Dicken P 2003 Global shift: reshaping the global economic map in the 21st century Sage, London

Dodgshon RA 2008 'Geography's place in time' Geografiska Annaler, Series B: Human Geography 90, 1-15

Dodson B 1998 Women on the Move: Gender and Cross-Border Migration to South Africa, Southern African Migration Programme, Idasa, Cape Town

Dornan P 2010 Understanding the impacts of crisis on children in developing countries, Young Lives Round 3 Preliminary Findings, Oxford

Dyer K 2001 Gender relations in the home and the workplace in Lesotho Institute of Southern African Studies, Roma, Lesotho

Ellegård K and Vilhelmson B 2004 'Home as a pocket of local order: Everyday activities and the friction of distance' Geografiska Annaler, Series B: Human Geography 86, 281-296 
Ansell N, Tsoeu-Ntokoane S and Hajdu F (in press and online) 'Women's changing domestic responsibilities in neoliberal Africa: a relational time-space analysis of Lesotho's garment industry' Gender, Place and Culture

Elson D 1999 'Labor markets as gendered institutions: equality, efficiency and empowerment issues' World Development 27(3), 611-627

Epprecht M 2000 'This matter of women is getting very bad': gender, development and politics in colonial Lesotho University of Natal Press

Eraydin A and Erendil A 1999 'The role of female labour in industrial restructuring: new production processes and labour market relations in the Istanbul clothing industry' Gender, Place and Culture 6(3), 259-272

Gay J S 1980 Basotho women's options: a study of marital careers in rural Lesotho PhD Thesis, University of Cambridge

Gibb R 2003 'Globalisation and Africa's economic recovery: a case study of the European Union-South Africa post-Apartheid trading regime' Journal of Southern African Studies 29(4), 885-901

Government of Lesotho 2012 'Why Invest In Lesotho - Competitive Business Costs' Ministry of Trade and Industry, Cooperatives and Marketing, http://www.trade.gov.ls/invest/competiveness.php, accessed 14/02/2012,

Green L 2003 'Notes on Mayan youth and rural industrialization in Guatemala' Critique of Anthropology 23(1), 51-73

Hajdu F, Ansell N, Robson E, van Blerk L and Chipeta L 2011 'Income-generating activities for young people in southern Africa: exploring AIDS and other constraints' Geographical Journal 177(3) 251-263

Harrison G 2010 Neoliberal Africa: the impact of global social engineering Zed, London

Hausmann R, Tyson L and Zahidi S 2011 The Global Gender Gap Report, World Economic Forum, Geneva

Heintz J 2004 'Beyond sweatshops: employment, labor market security and global inequality' Antipode 36(2), 222-226

Hewamanne S 2006 '"Participation? My blood and flesh is being sucked dry": Market-based development and Sri Lanka's Free Trade Zone women workers' Journal of Third World Studies 23(1) 51-74 
Ansell N, Tsoeu-Ntokoane S and Hajdu F (in press and online) 'Women's changing domestic responsibilities in neoliberal Africa: a relational time-space analysis of Lesotho's garment industry' Gender, Place and Culture

Kabeer N 2000 The power to choose: Bangladeshi women and labour market decisions in London and Dhaka Verso, London

Kabeer N 2008 'Paid work, women's empowerment and gender justice: critical pathways of social change, Pathways Working Paper 3, Institute of Development Studies, University of Sussex, Brighton

Kaplinsky R 2008 'What does the rise of China do for industrialisation in sub-saharan Africa?' Review of African Political Economy 35(115), 7-22

Katz C 2001 'Vagabond capitalism and the necessity of social reproduction' Antipode 33(4), 708727

Katzman R 1992 'Why are men so irresponsible?' CEPAL Review 46, 79-87

Kelly P 2009 'From global production networks to global reproduction networks: households, migration, and regional development in Cavite, the Philippines' Regional Studies 43(3), $449-461$

Khosla N 2009 'The ready-made garments industry in Bangladesh: A means to reducing genderbased social exclusion of women?' Journal of International Women's Studies 11(1) 289303

Kimane I and Mohale N 2007 'Grandmothers and grandchildren: living arrangements and relationships of orphaned children in Lesotho' in Mapetla M, Schlyter A and Bless B eds Urban experiences of gender, generations and social justice ISAS, Roma, Lesotho

Kimane I and Ntimo-Makara M 1998 'The gender dimension of urban migration in Lesotho' in Larsson A, Mapetla M and Schlyter A (eds) Changing gender relations in southern Africa: issues of urban life ISAS, Roma, Lesotho

Lefko-Everett K 2007 Voices from the margins: migrant women's experiences in southern Africa Southern African Migration Programme, Idasa, Cape Town

Kingdom of Lesotho 2006 Poverty Reduction Strategy 2004/5 - 2006/7, Maseru

Kingdom of Lesotho 20072006 Lesotho census of population and housing: preliminary results report, Bureau of Statistics, Maseru

Lauby J and Stark O 1988 'Individual migration as a family strategy: young women in the Philippines' Population Studies 42( 3), 473-486 
Ansell N, Tsoeu-Ntokoane S and Hajdu F (in press and online) 'Women's changing domestic responsibilities in neoliberal Africa: a relational time-space analysis of Lesotho's garment industry' Gender, Place and Culture

Lawson V A 1998 'Hierarchical households and gendered migration in Latin America: feminist extensions to migration research' Progress in Human Geography 22(1), 39-53

Mapetla and Sakoane-Songca 2005 'Perceptions on property and inheritance rights in Lesotho: need for legal change?' in Kalabamu F, Mapetla M and Schlyter A eds Gender, generations and urban living conditions in southern Africa ISAS, Roma, Lesotho

Massey D 2005 For space Sage, London

Mattoo A, Roy D and Subramanian A 2003 'The Africa Growth and Opportunity Act and its rules of origin: generosity undermined?' World Economy 26, 829-851

Mills MB 1999 Thai women in the global labor force Rutgers University Press

Mitchell P 2008 'Not so automatic: The contingent role of Auckland's local government in the region's information and communications technologies infrastructural development' Social and Cultural Geography 9(6), 693-710

Murray C 1981 Families divided: the impact of migrant labour in Lesotho Cambridge University Press, Cambridge

Ong A 1987 Spirits of resistance and capitalist discipline: factory women in Malaysia SUNY Press

Panelli R 2007 'Time-space geometries of activism and the case of mis/placing gender in Australian agriculture' Transactions of the Institute of British Geographers 32, 46-65

Pearson R 1998 "Nimble fingers' revisited: reflections on women and Third World industrialisation in the late twentieth century' in Jackson C and Pearson R (eds) Feminist visions of development: gender analysis and policy Routledge, London, pp 171-188

Peck J and Tickell A 2002 'Neoliberalising space' Antipode 34(3), 380-404

Pribilsky J 2001 'Nervios and 'modern childhood': migration and shifting contexts of child life in the Ecuadorian Andes' Childhood 8(2), 251-273

Ruddick S 2003 'The politics of aging: globalization and the restructuring of youth and childhood' Antipode 35(2), 334-362

SADC 2004 'SADC Trade, Industry and Investment Review' http://www.sadcreview.com, accessed 27th November 2004, 
Ansell N, Tsoeu-Ntokoane S and Hajdu F (in press and online) 'Women's changing domestic responsibilities in neoliberal Africa: a relational time-space analysis of Lesotho's garment industry' Gender, Place and Culture

Salm A, Grant W J, Green T J, Haycock J R and Raimondo J 2002 Lesotho garment industry subsector study for the Government of Lesotho Funded by DFID, Maseru

Seyoum B 2007 'Export performance of developing countries under the Africa Growth and Opportunity Act: Experience from US trade with Sub-Saharan Africa' Journal of Economic Studies 34(6), 515-533

Silvey R M 2001 'Migration under crisis; household safety nets in Indonesia's economic collapse' Geoforum 32, 33-45

Standing G 1999 'Global feminisation through flexible labour: a theme revisited' World Development 27, 535-550

Steans J and Tepe D 2010 'Introduction - Social reproduction in international political economy: theoretical insights and international, transnational and local sitings' Review of International Political Economy 17(5), 807-815

Sweetman C (ed), 1997 Men and masculinity Oxfam, Oxford

Tiano S 1994 Patriarchy on the line: labor, gender and ideology in the Mexican maquila industry Temple University Press, Philadelphia

Traub-Werner M and Cravey A J 2002 'Spatiality, sweatshops and solidarity in Guatemala' Social and Cultural Geography 3(4), 383-401

Ulicki T and Crush J 2007 'Poverty, gender and migrancy: Lesotho's migrant farmworkers in South Africa' Development Southern Africa 24(1) 155-172

UNAIDS 2010 Report on the global AIDS epidemic UNAIDS, Geneva

UNDP 1998 Human Development Report, Lesotho UNDP

UNDP 2012 'International human development indicators' http://hdr.undp.org/en/data/, accessed $14 / 02 / 2012$,

Waldfogel J 2002 'Child care, women's employment, and child outcomes' Journal of Population Economics 15(3), 527-548

Wallengren K 2009 'Follow-up HIV sero-prevalence study report' Apparel Lesotho Alliance to Fight AIDS (ALAFA), Maseru, Lesotho 
Ansell N, Tsoeu-Ntokoane S and Hajdu F (in press and online) 'Women's changing domestic responsibilities in neoliberal Africa: a relational time-space analysis of Lesotho's garment industry' Gender, Place and Culture

Webber G, Edwards N, Graham ID, Amaratunga C, Keane V and Socheat R 2010 'Life in the big city: the multiple vulnerabilities of migrant Cambodian garment factoryworkers to HIV' Women's Studies International Forum 33(3) 159-169

Werner M 2010 'Embodied negotiations: Identity, space and livelihood after trade zones in the Dominican Republic' Gender, Place and Culture 17(6) 725-741

Wolf D 1992 Factory daughters: gender, household dynamics and rural industrialisation in Java Oxford University Press, Oxford

Young L and Ansell N 2003 'Fluid households, complex families: the impacts of children's migration as a response to HIV/AIDS in southern Africa" Professional Geographer $55(4), 464-479$

Zappile T M 2011 'Nonreciprocal Trade Agreements and Trade: Does the African Growth and Opportunity Act (AGOA) Increase Trade?' International Studies Perspectives 12(1), 4667 